\title{
Idiom Teaching and Learning in Vietnam: Challenges and Activities
}

\author{
Nam Quang Pham ${ }^{1 *} \quad$ Lien My Tran ${ }^{2}$ \\ Department of Foreign Languages, University of Medicine and Pharmacy at Ho Chi Minh City \\ 217 Hong Bang, District 5, Ho Chi Minh City, Vietnam
}

\begin{abstract}
The demands for learning English as a foreign language have been increasing over the last fifteen years in Vietnam. It is commonly believed that idiomatic expressions are not important in learning English as a foreign language. Strutz (1996), however, maintained that "no one can be said to be really proficient in a language until he or she possesses an idiomatic command of it" (vii). Drawing from relevant research and studies in the field of figurative language acquisition, this paper aims to present current issues of teaching and learning idiomatic language in Vietnam followed by some recommended teaching activities.
\end{abstract}

Keywords: idiom, idiomatic language, idiomatic competence

DOI: $10.7176 / \mathrm{JLLL} / 67-04$

Publication date: April $30^{\text {th }} 2020$

\section{Introduction}

Despite constant change in language, there are fixed expressions which specifically establish idioms. An idiom is defined as "a group of words that has a special meaning different from the ordinary meaning of each separate word" (Longman Dictionary of Contemporary English, 2009, p. 870). Idioms exist in all languages and "enjoy widespread use among speakers of every language the world over" (D'Angelo Bromley, 1984, p. 272). Idioms make use of mental pictures to create certain meanings. For instance, "the grass is always greener on the other side of the fence" refers to the way some people look at other people's lives and other things that they do not have. For non-native students, understanding such idioms can be a challenge. This paper aims to present some challenges in figurative language acquisition and propose four practical teaching activities for language educators in Vietnam.

\section{Importance of Teaching Idioms}

Teaching idioms should have a role in language curriculum in Vietnam for two reasons. First, given the wide usage of idioms by native speakers, it is necessary language learners be prepared with the meaning of figurative expressions. Lundblom and Wood (2012) stated idioms are widely used in daily conversations, newspaper, and public media. Cooper (1998) believed when idioms appear in TV show, the viewers need to be able to comprehend the idioms to understand the plot. Burke (1998) emphasized "there is absolutely no way a nonnative speaker of English could fully understand an American movie, TV show, news broadcast, or even a typical conversation without help because our language is loaded with non-standard English, i.e., slang and idioms" (p. 1). He maintained if non-native speakers are unable to comprehend idioms, they will always remain as outsiders. Cooper (1998) remarked "sooner or later, imprecise idiomatic usage will cause difficulties even for a student with an excellent knowledge of grammar and a high level of vocabulary attainment" (p. 259). Taking these viewpoints together, it becomes evident that idiomatic expressions should have a critical place in the process of language learning. Second, due to the challenges of using idioms competently, idioms should be covered in language learning. As D'Angelo Bromley (1984) explained, idioms "add confusion and difficulties to the learning of language" (p. 272). Lack of idiom practice in language curriculum may present some hardship for non-native speakers when they have to use the target language in an authentic environment. Due to its importance as well as challenges, teaching idioms should not be neglected or ignored in language curriculum.

\section{Challenges of Teaching Idioms in Vietnam}

In Vietnam, with the implementation of The National Foreign Languages 2020 Project, idiom learning has received a higher level of attention. This project states English language learners in Vietnam-depending on the academic degree and major they are seeking - must meet an international standard in the Common European Framework of Reference for Languages (CEFR). This framework describes language ability on a six-point scale, ranging from $\mathrm{A} 1$ (beginners) to $\mathrm{C} 2$ (advanced). For instance, undergraduate student language ability must be within B1 to B2 level in the CEFR or equivalent. The ability to use figurative expressions is stated in one of the CEFR indicators. Intermediate language users should be able to listen and "understand a wide range of idiomatic expressions and colloquialisms" (Council of Europe, 2012, p. 66). In daily conversations, they should demonstrate the capability of using "some less common and idiomatic vocabulary" (British Council, p. 1). Despite these requirements, not many English teachers in Vietnam are fully aware of the importance of idioms in 
language use. As Tran (2012) pointed out, most of them have difficulties selecting appropriate teaching materials as well as engaging students in authentic usage of English idioms.

Other challenges can also impede English as a Foreign Language (EFL) student acquisition of idiomatic expressions. The dimension of semantic opacity, structural and conventionalized pragmatics (Liontas, 2002) can lead to comprehension problems for language learners. When encountering idioms, EFL speakers need to figure out the non-literal meanings. For instance, "my cup of tea" as in "People like swimming, but it is not my cup of tea" has nothing to do with drinking. In this case, non-native speakers need to make mental efforts in making sense of "cup of tea" because its figurative meaning refers to something that someone finds pleasing. Native speakers, however, can realize its meaning quickly without any mental effort. In addition, EFL students in Vietnam do not have much exposure to interactive situations in which idioms are used. English is not a second language in Vietnam and students' learning English is limited to classroom settings and textbooks. When talking to Vietnamese people, native speakers of English prefer using plain English rather than figurative language to avoid misunderstanding.

\section{Idiomatic Competence}

Liontas (2012) defined idiomatic competence as "the ability to understand and use idioms appropriately and accurately in a variety of sociocultural contexts, in a manner similar to that of native speakers, and with the least amount of mental effort" (p. 167). Figurative or idiomatic competence has received greater attention in recent years together with communicative competence. Celce-Murcia (2008) revised a model of communicative competence in which the ability to use to idioms is a component of formulaic competence. She noted formulaic competence involves the use of fixed chunks or stretches of language in communication. According to Buckingham (2006), idiomatic competence refers to the ability to communicate with idioms in the roles of both an addressor and an addressee, which is considered as part of formulaic competence. In this way, people engaged in communication can convey and comprehend the meaning of conversation.

The learning process has to go through five steps including familiarization, recognition, comprehension, mastery and automaticity (Knowles, 2004). In the final step, learners can confidently use the L2 and automaticity can be reached through phases of practicing and being exposed to the target language. Knowles's proposal of a learning process model pointed out learners need to be given chances to interact and practice idiomatic expressions in an intensive way so that they can develop the ability to use idioms in authentic communication.

Idiomatic expressions need to be taught so that learners can develop idiomatic competence. Nation and Meara (2002) considered explicit and incidental learning as two methods of acquiring idiomatic expressions. Explicit learning is more goal-oriented than incidental learning. Explicit learning pays more direct attention to the information to be learned, thus allows greater chances for the acquisition of idiomatic expressions. For learners to better acquire idioms, language teachers should maximize students' exposure to the idioms and highlight them when necessary.

When teaching idiomatic expressions, language teachers may consider using context, illustration, and discussion. First, a rich context will assist language learners in making sense of unknown words or phrases. Nippold and Martin (1989) supported the use of contextual cues because they could help readers get the meaning and enhance the interpretation of language idioms. Brown (2001) indicated if language learning occurs in a context-reduced form, it will be hard for learners to acquire. Second, the incorporation of visual aids into language teaching can improve student comprehension of idiomatic expressions. Zadina (2004) suggested teachers should try to turn ideas into images or ask the students to show their images of that idea. She also posited the visual should be tied together with the auditory and speech modalities, so that students can also produce the things they see or hear. Scarcella and Oxford (1992) asserted vocabulary instruction would be more effective if pictures or diagram were used to facilitate students' comprehension. Additionally, students' comprehension of idiomatic expressions will be improved if they are engaged in classroom discussions where they can exchange information and negotiate meanings with their peers. As Klingner and Vaughn (2000) believed, if students are engaged in collaborative talk in the content reading stage, they can help each other to make sense of difficult words, catch the main ideas or even find the answers to some questions they have. Therefore, idiom teaching and learning should not be considered as a separate activity. It should be integrated into teaching language skills with the assistance of contexts, visuals and collaboration.

\section{Suggestions and Recommendations}

Since it is not an easy task to resolve challenges of teaching idioms in Vietnam, this paper does not attempt to address improvements in a macroscopic level. Drawing from the theoretical framework of idiomatic competence, four teaching activities - each is particularly designed for a level—are suggested in this section. It is expected that these activities can provide more opportunities for EFL students in Vietnam to practice figurative language. To engage students in idiom learning activities, language educators should identify which idiomatic expressions to be taught by following this proposed guideline. First, students need to be prepared with frequently used idioms 
in daily conversations and written texts. Consulting with native speakers of English for such idioms-though sometimes may be subjective - can be feasible when it is hard to find official resources with high-frequency lists of English idioms. It is not difficult to find native speakers of English in Vietnam nowadays because the Vietnamese government is implementing a project that welcomes native freelancers for English language teaching. Commonly used idioms such as "once upon a time" or "piece of cake" should be on the top of the list to be taught. Second, language teachers should consider the transparency when choosing idiomatic learning contents. Some idioms such as "the grass is always greener on the other side" should receive higher attention than "kill two birds with one stone". In addition, the appropriateness of idiomatic expressions should be reviewed because the usage of certain idioms is limited to colloquial/slang or uncommon to native speakers of English. Furthermore, idioms with student first language (L1) equivalence should be taught because it can arouse their interests. EFL students in Vietnam, for example, may be interested in "take coals to Newcastle" because of an equivalence of "take wood back to forests" in their L1.

The section below proposes four activities for different levels so that language teachers in Vietnam can insert idiom teaching into their classrooms.

\subsection{Activity 1}

\subsubsection{Description}

- Level: elementary English learners

- Instructional objectives: Students will draw pictures for idioms and practice recognizing an idiom when they hear one. Students will be able to come up with a meaning for an idiom and use it communicatively.

- Materials: Drawing paper, clipboards, drawing tools, whiteboards

- Time: To be determined by the teacher

- Type: This activity is communicative and focuses on listening and speaking skills. Students need cooperation to complete the tasks. This activity requires no prior knowledge and can be recycled with other idioms that are demonstrated visually.

5.1.2 Activity Outline

Depending on the class size, the teacher can divide the class into different groups with 3 members each. Each group will receive drawing paper and drawing tool. The teacher shows some idioms on whiteboard such as:
The big goose egg
A fish out of water
A little bird told me

Could eat a horse

The teacher asks each group to choose one idiom from the list and draw a picture showing a literal meaning for that idiom. Students can add other details or design the picture with their imaginativeness.

Students will then be asked to post the pictures around the classroom. The teacher will go through each picture and ask students to look and repeat the idioms. Students will be provided with simple definition for each idiom such as "very hungry" for a picture of a person trying to eat a horse. The teacher will go over once again to make sure students understand the meaning for each picture that they encounter on the wall.

The teacher will ask students where each idiom may be heard or written. For instance, "goose egg" can be used when talking about sport events, money, school exams.

Students will be asked to work in groups to make conversations or dialogues that contain idioms they have just learnt. Then, they will act out their conversations in front of the class. Then, the teacher will take notes of their mistakes and provide feedback.

\subsection{Activity 2}

\subsubsection{Description}

- Level: pre-intermediate English learners

- Instructional objectives: Students will be able to demonstrate understanding of eight idioms by drawing and having small group discussions.

- Materials: Number cards, hat, blank papers, colored pencils, letter cards and sheets of note book paper

- Time: Approximately 60 minutes

- Type: This activity is communicative and focuses on speaking and writing skills. Students need cooperation and discussion to complete the tasks. This activity does not require prior knowledge and can be recycled with other idioms. Each group will be graded with their final language production.

\subsubsection{Activity Outline}

The teacher shows the following idioms on the board, ask students to read and look up new words in regular dictionary. Students will talk to each other about what they have learnt.
1. barking up the wrong tree
2. cat got your tongue
3. cry over split milk
4. drive me up the wall
5. have an axe to grind
6. jump the gun 
7. on pins and needles

8. X marks on the spot

The teacher will create four sets of cards for thirty-two students in class; each set has eight cards numbered from 1 to 8 . Each student will receive a card that contains a number. Then, they have to study the idiom that coincides with the number on their card and draw an exact representation of that idiom on a paper. For instance, the student with number 7 needs to draw a person lying on many pins and needles.

Once all pictures are complete, students will form eight groups based on the number on their cards. For example, students who has number one on their card will sit together. In this group, they will share their pictures with other members and identify a common meaning for the idiom they are working on. Each student has to make at least four sentences and write them down at the back of their picture. At this stage, the teacher should move around groups to make sure students are making right sentences and completing the activity accurately.

Finally, each student will be given another card that contains letter A, B, C or D to form larger groups. In this group, students will share their idioms, their pictures, and their sentences. They will be discussing and sharing information with other members and the group must vote for sentences that can represent the idioms that they are working on. They will transfer these sentences to a notebook and exchange with other groups. The teacher can collect the papers for assessment when students leave class.

\subsection{Activity 3}

\subsubsection{Description}

- Level: intermediate English learners.

- Instructional objectives: Students will practice recognizing and explaining the meaning of common idioms, both literally and figuratively. Students will complete a visual project that helps to promote their understanding the difference between the literal and figurative meaning of idioms that they have chosen.

- Materials: Worksheet, videos, images, handouts, drawing paper.

- Time: To be determined by the teacher

- Types: This activity is communicative and focuses on reading, speaking and writing skills. Students need cooperation and mental image to complete the tasks. This activity requires some prior knowledge and can be recycled with other idioms that are demonstrated visually. Students will be graded with rubrics, depending on their ability to demonstrate their mental image.

5.3.2 Activity Outline

The teacher will begin the activity by eliciting students' prior knowledge of some native phrases or sentences that can be heard in Vietnam such as "last straw" or "let the cat out of the bag." Students will work in small groups to brainstorm some phrases that they know. The teacher will get students' response and explain that each language has idioms and each idiom will have both literal and figurative meaning. Then, the teacher will transition into the lesson.

Students will read the "Idioms for Idiots" by John Randal and highlight or underline any idioms that they identify in this poem. This activity can be recycled with other idiom poems found on http://www.poetrysoup.com/poems/idiom.

\section{IDIOMS FOR IDIOTS}

'You can't cry over spilled milk!'

my mother always said.

'Life's not a piece of cake! '

she hammered in my head.

'That's the way it goes,

'that's the way the cookie crumbles'

My mother saved her idioms

for all my idiotic troubles.

John Randal

Students will work in pairs to determine the literal and figurative meanings of idioms that they highlighted. At this time, the teacher will go around and provide feedback by asking questions for clarification such as "Why did you choose that phrase?" or "Have you ever heard of these phrases before?".

Then, the teacher will explain idioms have both literal and figurative meaning. Some photos can be shown to demonstrate students can draw pictures to express both literal and figurative meanings of an idiom.

Teachers can go over the meanings of idioms found in "Idioms for Idiots" poem. A visual illustration similar to the example of "jump on the bandwagon" can help students have better understanding of meanings, create mental image in students' mind and guide them in the practice section.

Students will work with their partners to complete the literal and figurative meaning for selected idioms. They can work in larger groups to discuss their explanations and interpretations. The teacher should monitor students during these discussion times and provide corrective feedback as needed. Once students have completed 
the table, the teacher will check the answer for the whole class to make sure each student has the correct meanings. Finally, each pair will pick up one idiom from the table and draw two pictures, one for literal and the other for figurative meaning. The teacher may provide drawing papers and pencils as needed. Upon completion, students will hang their pictures around classrooms for their peer review. The teacher can grade students' work.

\subsection{Activity 4}

\subsubsection{Description}

- Level: upper-intermediate English learners

- Instructional objectives: Students will practice guessing the figurative meaning of idioms based on the visual aids and contexts. Students will also be able to use idioms in an authentic way when they take part in discussion.

- Materials: Pictures, projector, computer, textbook

- Time: To be determined by the teacher

- Type: This activity is communicative and contextualized. Students have to think and guess meaning from the clues (visuals and contexts) given. This activity requires some prior knowledge and can be recycled with other pictures found on http://www.visual-idioms.com.

5.4.2 Activity Outline

The teacher tells the students they are going to learn a new idiom. It is helpful if students are reminded of the definition of an idiom. They should be able to explain the differences between literal and figurative meaning of an idiom.

The teacher will show the pictures one by one. For each picture, students will be asked to describe it in detail, either in pairs or groups. The teacher will elicit words related to the image and write them on the board. Then, the teacher will ask students if they can guess the idiom with the words they got. It is better if more responses are elicited at this stage. Funny responses such as "feel like a pair of shoes on a clothesline" should be welcome. For example, when teaching the idiom "hang somebody out to dry", the teacher can write this idiom on the board and discuss its literal meaning orally. Then, the teacher may ask if students can guess the figurative meaning. If they are unable to do so, the teacher can give some context for guessing with some examples such as "Once I find out who has vandalized my house, I swear I will hang them out to dry" or "How would you feel hanging out on a clothesline? Would it be a reward or a punishment for you?" In this way, the literal meaning is being put next to figurative meaning. The teacher may continue with more examples or explanations until students can figure out the correct figurative meaning.

To encourage students to use idioms in authentic settings, the teacher can suggest some questions for group discussions such as "Have you ever hung someone out to dry for something? If yes, what did you do?" or "Would you like to hang somebody out to dry? What for?". Students should be encouraged to actively participate in the discussion and give responses. In this way, they are utilizing the idioms in authentic contexts.

Students should also be reminded of the grammatical features of that idiom so that they can use it in an accurate way, both syntactically and semantically. The activity can be made more interesting when students are required to find the corresponding idioms in their home language. They need their prior knowledge and they can compare the linguistic similarity between L1 and L2.

\section{Conclusion}

Although learning idioms can be a challenge for non-native speakers of English, it does not mean figurative language should be avoided in EFL classes. To improve the situation of learning idioms, idiomatic expressions should play a significant role in language teaching and learning. Language teachers should have a clear guideline for idiom selection so that students are prepared with commonly used idioms and able to utilize them in multiple contexts. Furthermore, communicative strategies with visual supports for idiomatic learning should be considered for facilitating classroom instructions. These strategies seek to build up more confidence for Vietnamese students in understanding and using figurative language.

\section{References}

British Council. IELTS speaking band descriptors (public version). Retrieved from http://www.britishcouncil.org/srilanka-exams-ielts-descriptor-speaking.pdf

Brown, H. D. (2001). Teaching by principles: An interactive approach to language pedagogy. New York, NY: Longman.

Buckingham, L. (2006). A multilingual didactic approach to idioms using a conceptual framework. Language Design, 8, 35-45.

Burke, D. (1998). Without slang and idioms, students are "in the dark!". ESL Magazine, 1(5), $20-23$.

Celce-Murcia, M. (1995). Communicative competence: A pedagogically motivated model with content specifications. Issues in Applied Linguistics, 6(2), 5-35. 
Cooper, C. (1998). Teaching idioms. Foreign Language Annals, 31(2), 255-266.

Council of Europe. (2012). The common European framework in its political and educational context. Retrieved from http://www.coe.int/t/dg4/linguistic/Source/Framework_en.pdf

D'Angelo Bromley, K. (1984). Teaching idioms. The Reading Teächer, 38(3), 272-276.

Klingner, J. K., \& Vaughn, S. (2000). The helping behaviors of fifth graders while using collaborative strategic reading during ESL content classes. TESOL Quarterly, 34(1), 71- 98.

Knowles, L. (2004). The evolution of CALL. The Journal of Communication \& Education: Language Magazine, $1-8$.

Liontas, J. (2002). Vivid phrasal idioms and the lexical-image continuum. Issues in Applied Linguistic, 13(1), 59-97.

Liontas, J. (2012). Context and idiom understanding in second languages. In S. H. Foster-Cohen, T. Ruthenberg, \& M-L. Poschen (Eds.), EUROSLA Yearbook: Annual Conference of the European Second Language Association, 2, 155-185.

Longman Dictionary of Contemporary English (2009). Word defined "idiom" (5th ed). Pearson Education Limited, p. 870.

Lundblom, E., \& Woods, J. (2012). Working in the classroom: Improving idiom comprehension through classwide peer tutoring. Communication Disorders Quarterly, 33, 202-219. Nation, P \& Meara, P. (2002). Vocabulary. In N. Schimitt (Ed.), An introduction to applied linguistics, 35-54. London, England: Routledge.

Nippold, M. A., \& Martin, S. T. (1989). Idiom interpretation in isolation versus context: A developmental study with adolescents. Journal of Speech and Hearing Research, 32, 59-66.

Scarcella, R. C., \& Oxford, R. L. (1992). The tapestry of language learning: The individual in the communicative classroom. Boston, MA: Heinle \& Heinle.

Strutz, H. (1996). German idioms. Hauppauge, NY: Barron's Educational Series.

Tran, H. Q. (2012). An explorative study of idiom teaching for pre-service teachers of English. English Language Teaching, 5(12), 76-86.

Zadina, J. N. (2004). Brain research-based effective strategies to enhance learning and energize instruction. Paper presented at the U.S. Department of Education Office of English Language Acquisition Summit Conference. 